\title{
FORUM
}

\section{Eicosanoids in Insect Biology}

\author{
David W. Stanley ${ }^{1}$, A.R. Nor Aliza ${ }^{1}$, Hasan Tunaz ${ }^{2}$, Sean M. Putnam ${ }^{1}$, Younguin Park ${ }^{3}$ \\ AND JON C. BEDICK ${ }^{1}$ \\ ${ }^{1}$ Insect Biochemical Physiology Laboratory, University of Nebraska, Lincoln, Ne 68583-0816 \\ ${ }^{2}$ Dept. Plant Protection, KahramanMaras Sutcu Imam University, KahramamMaras, Turkey \\ ${ }^{3}$ Andong National University, Andong, Korea
}

Eicosanóides na Biologia de Insetos

\begin{abstract}
RESUMO - Prostaglandinas e eicosanóides relacionados são metabolitos oxigenados de certos ácidos graxos poli-insaturados $\mathrm{C} 20$. Eicosanóides são melhor entendidos em relação à sua significância clínica em medicina humana. Sugerimos um novo e mais amplo significado para os eicosanóides, o qual chamamos 'paradigma biológico'. Sob esse aspecto, notamos que eicosanóides desempenhavam funções como sinalizadores celulares antes da origem dos Metazoa. Durante a diversificação evolucionária dos animais, os eicosanóides têm sido envolvidos em uma serie de funções biológicas, algumas das quais ocorrendo somente em insetos e em outros invertebrados. Essas ações múltiplas dos eicosanóides permitem o melhor entendimento dos fenômenos biológicos. Para desenvolver essas idéias nós revisamos os papéis dos eicosanóides em duas áreas da biologia de invertebrados: mediação das reações da imunidade de insetos a bactérias e interações hospedeiro-parasita. Numa visão ampla, os eicosanóides desempenham importantes funções na organização biológica ao nível das células, dos organismos e das interações ecológicas. Sugerimos que os questionamentos contínuos sobre a significância dos eicosanóides levarão a novos entendimentos na biologia dos insetos.
\end{abstract}

PALAVRAS-CHAVE: Imunidade de insetos, parasitologia, prostaglandinas.

\begin{abstract}
Prostaglandins and related eicosanoids are oxygenated metabolites of certain C20 polyunsaturated fatty acids. Eicosanoids are best understood in the context of their clinical significance in human medicine. We suggest a new and broader view of eicosanoids, which we have been calling a 'biological paradigm'. Under this view, we note that eicosanoids were taken into roles as cellular signal moieties long before the origins of the Metazoa. During the evolutionary diversification of animals, eicosanoids have been recruited into an array of biological roles, some of which occur only in insects and other invertebrates. These multiple actions endow eicosanoids with unusual explanatory power in understanding biological phenomena. We review the roles of eicosanoids in two areas of invertebrate biology: mediation of insect immune reactions to bacteria and host-parasite interactions. Seen broadly, eicosanoids play important roles at the cellular, organismal and ecological levels of biological organization. We suggest that continued inquiry into the significance of eicosanoids will yield important new insights into insect biology.
\end{abstract}

KEY WORDS: Insect immunity, parasitology, prostaglandins.

Most of us are familiar with prostaglandins (PGs) because they mediate discomforts associated with inflammation and minor injury, and because the over-the-counter analgesics we ingest to relieve discomforts, such as aspirin, act by inhibiting PG biosynthesis. PGs make up one group of a larger class of compounds collectively known as eicosanoids. The term eicosanoid was originally coined by Corey and his colleagues (Corey et al. 1980) to refer to all oxygenated metabolites of certain C20 polyunsaturated fatty acids. There are three major groups of eicosanoids, including the PGs, the epoxyeicosatrienoic acids, and the many lipoxygenase products. Specific metabolic pathways are responsible for biosynthesis of each group of eicosanoids (Fig. 1).

Reference to pharmaceutical analgesics is meant to highlight the most widely appreciated significance of eicosanoids: these compounds exert potent actions in human physiology and pathophysiology. Indeed, the very term PG reflects the origins of research on eicosanoids, which arose in studies of human reproductive biology. Von Euler (1936) first published the term PG because the substances responsible for stimulating uterine muscle contraction were associated with the prostate gland. Similarly, another group of 


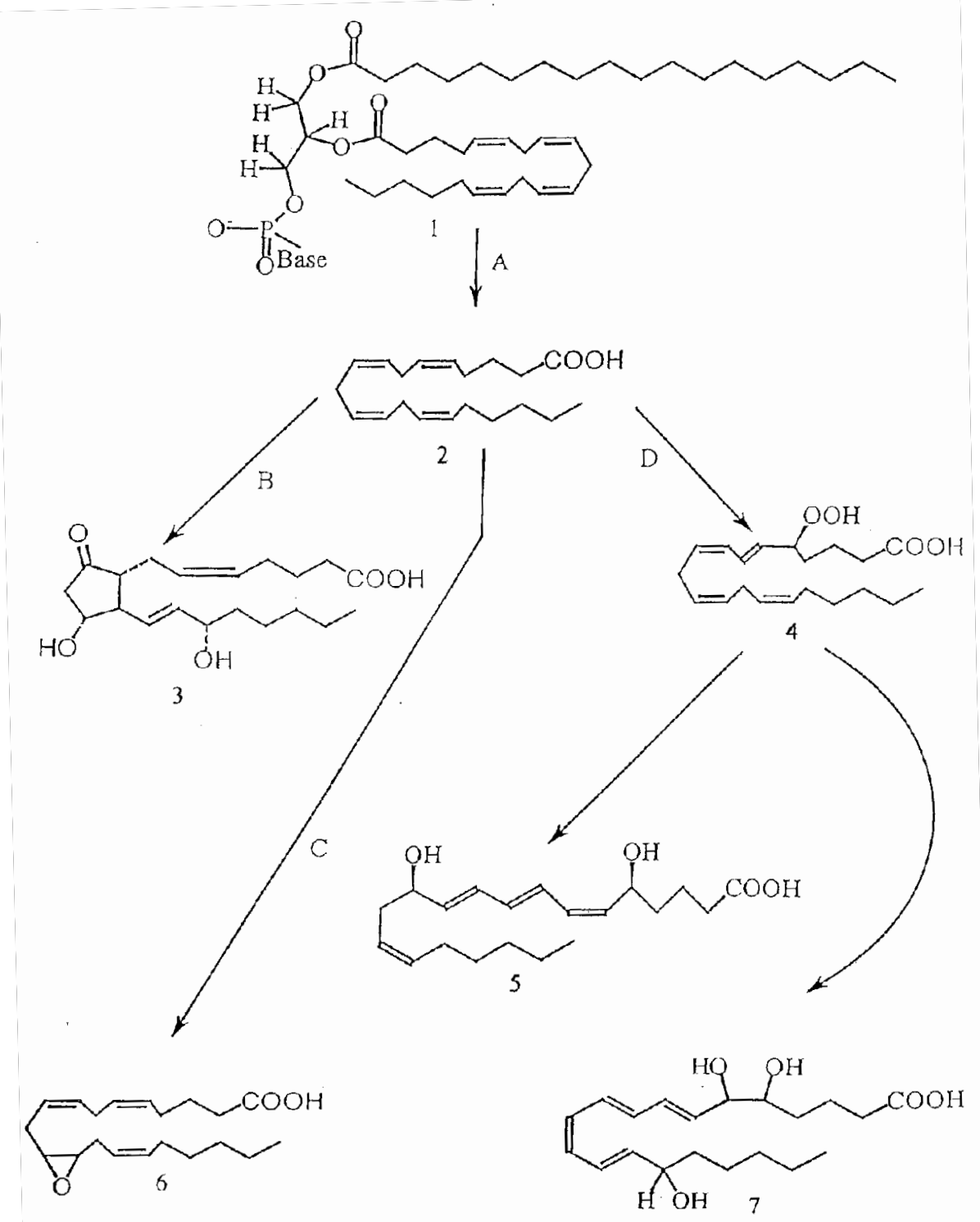

Figure 1. An overview of 20: $4 \mathrm{n}-6$ metabolism as understood from the mammalian background. Three polyunsaturated fatty acids, 20: 3n-6, 20: 4n-6 and 20: 5n-3 are potential substrates for eicosanoid biosynthesis. Of these, metabolism of 20: $4 \mathrm{n}-6$ is most well studied. Chemical structures are denoted by numerals. $1=$ a cellular phospholipid. $2=$ hydrolyzed 20: $4 \mathrm{n}$ $6.3=$ prostaglandin $\mathrm{E}_{2} .4=5$-hydroperoxyeicosatetraenoic acid. $5=$ leukotriene $\mathrm{B}_{4} \cdot 6=11,12$-epoxyeicosatrienoic acid. $7=$ lipoxin A. Capital letters indicate major enzyme systems responsible for eicosanoid biosynthesis. $\mathrm{A}=$ phospholipase $\mathrm{A}_{2}$; $\mathrm{B}$ $=$ cyclooxygenase and associated enzyme steps; $\mathrm{C}=$ cytochrome $\mathrm{P}_{450}$ epoxygenase; $\mathrm{D}=$ lipoxygenase.

eicosanoids, the leukotrienes, were so named because they are trienoic acids produced in human leukocytes (Samuelsson 1983). The chemical structures of some PGs were first determined in the 1960's (Bergstrom et al. 1962), from which it was inferred that PGs must be biosynthesized by oxygenation of $\mathrm{C} 20$ polyunsaturated fatty acids, particularly arachidonic acid (20: 4n-6). In contemporary idiom, studies of eicosanoid biosynthesis are often called arachidonate metabolism. Recognition of the pathophysiological significance of eicosanoids emerged from a now-classic series of experiments by Robert Vane. Vane showed that aspirin inhibits PG biosynthesis in a dose-dependent way. Bergstrom, Samuelsson and Vane later shared a Nobel Prize in Medicine or Physiology for their work on eicosanoids (Oates 1982). Again, these comments emphasize the human- or perhaps mammal-centered appreciation of the significance of eicosanoids.

The goal of this essay is to substantially broaden appreciation and interest in the biological significance of eicosanoids. In our view which we have been calling a 'biological paradigm', eicosanoids were biosynthesized and exerted regulatory actions in the earliest forms of animal life, those representing the unicellular phyla. By the time metazoan animals evolved, cells already had considerable experience in the synthesis and information content of eicosanoids. Recognizing that multicellular animals are far more complex 
than their unicellular progenitors, animal evolution provided abundant opportunity for recruiting eicosanoids into many biological roles. Virtually all known eicosanoid actions involve some form of signaling. The key point is that eicosanoids can signal events within cells, between cells, and between organisms. Eicosanoids act at several levels of biological organization, and they exert varying degrees of influence from subtle so-called "housekeeping" actions in homeostatic physiology to crucial events in life cycles. While the traditional mammal-centered view would suggest a similar appreciation for mammals, the biological paradigm guides us in thinking that eicosanoids act in all animals, and in some cases between populations of animals.

The idea that eicosanoids occur in invertebrates surfaced in 1969 with the discovery of high levels of certain PGs in a gorgonian octacoral, Plexaura homomalla, (Weinheimer \& Spraggins 1969). Methods for the chemical synthesis of PGs for research had not yet been invented, and the octacoral paper launched an intense search for other natural, and commercially useful, sources of PGs. Although none were found, the many ensuing reports inform us that PGs and other eicosanoids can be detected in virtually any animal taken under appropriate scrutiny.

The occurrence of PGs and other eicosanoids in invertebrates eventually begged the question of the biological significance of these compounds. What do these compounds do in invertebrates? Insects yielded the first insight into a biological role of eicosanoids in invertebrates. The late U.E. Brady suggested that certain PGs are partially responsible for inducing egg-laying behavior in newly-mated house crickets, Acheta domesticus (L.) (Destephano \& Brady 1977). We now know that eicosanoids act in many areas of invertebrate biology, including reproduction, ion transport, and peptide hormone signal transduction (Stanley 2000 and reviews cited therein). In this essay we discuss recent advances in two other important areas of insect biology, namely immunity and in host-parasite relationships.

\section{Eicosanoids in Insect Immunity}

Whereas some of the earliest experiments in immunity were carried out with invertebrates (Rowley 1996), their lack of specific acquired, or adaptive, immunity shifted interest from invertebrate to vertebrate immune systems. Nonetheless, it remains that both invertebrates and vertebrates express generalized innate, and very effective, immune reactions to infection. In insects and many other invertebrates these reactions include immediate cellular reactions such as phagocytosis, nodule formation, and encapsulation (Gillespie et al. 1997, Strand \& Pech 1995). Phagocytosis involves internalization of small particles, such as bacterial cells, by circulating hemocytes. Nodule formation clears large numbers of bacteria from hemolymph by entrapping the bacterial cells in microaggregates of hemocytes and bacterial cells. The microaggregates and their entrapped bacteria grow by attracting additional hemocytes and bacterial cells. They finally mature into nodules with a final layer of hemocytes, which are responsible for melanization of the nodules by activation of prophenoloxidase. Millions of circulating hemocytes are typically invested in these clearing reactions. Larger foreign bodies, such as the eggs of parasitoid insects, are encapsulated by succeeding layers of hemocytes. These, too, are melanized by a final layer of hemocytes.

The melanization step is driven via activation of prophenoloxidase, which entrains a complex series of biochemical pathways. In larvae of Drosophila melanogaster (Meigen), the innate cellular immune response that results in the formation of melanotic capsules around intrahemocoelic wasps (parasitoids) is accompanied by elevated levels of nitric oxide, superoxide anion and hydrogen peroxide, molecules implicated along with certain reactive quinonoid intermediates of melanin in the killing process (Carton \& Nappi 2001). Collectively, these host responses not only destroy the parasitoids, but also confine the cytotoxic activity within pigmented capsules, thereby protecting endogenous tissues from the biochemically hostile reactions directed against nonself entities. Invertebrates also express humoral reactions to infections which mostly involves induced biosynthesis of anti-bacterial proteins (Dunn 1986, Chernysh et al. 1996).

These observable immune reactions are well known, however, the signal transduction mechanisms responsible for initiating and coordinating these reactions are more obscure. We made the first inquiry into the biochemical signals that operate in invertebrate cellular immunity by investigating the roles of eicosanoids in clearing bacterial infections from hemolymph circulation in fifth stage tobacco hornworm, Manduca sexta L. We inferred that eicosanoids mediate cellular defense reactions to bacterial infections in insects and other invertebrates (Stanley-Samuelson et al. 1991). Nodulation is responsible for clearing the majority of invading bacterial cells from insect hemolymph circulation during the first $2 \mathrm{~h}$ postinfection (Horohov \& Dunn 1983), and we next hypothesized that nodulation is one of the cellular defense reactions mediated by eicosanoids (Miller et al. 1994). We tested this idea by treating experimental hornworms with an eicosanoid biosynthesis inhibitor, then infecting them with bacteria. Controls were treated with ethanol. At selected times postinfection, nodulation was assessed by counting the numbers of nodules. We recorded about 120 nodules/hornworm in ethanol-treated controls, and about 40 nodules/hornworm in experimental insects. The influences of the inhibitors were expressed in dose-dependent manners and could be reversed by treating experimental insects with arachidonic acid. Again, we inferred that eicosanoids mediate nodulation reactions to bacterial infections in insects (Miller et al. 1994).

Of course, it is difficult to extrapolate from findings based on a single moth species to the remainder of the class Insecta and from there to other invertebrate taxa. The protocols for assessing the roles of eicosanoids in nodulation reactions to bacterial infections are fairly straightforward (Miller \& Stanley 1998a), and we applied these protocols to insect species representing several major orders. Results from these exercises support the view that eicosanoids mediate nodulation reactions to bacterial infections in other lepidopterans, including silkworms, Bombyx mori (L.) (Stanley-Samuelson et al. 1997), true armyworms, Pseudaletia unipuncta (Haworth) and black cutworms Agrotis ipsilon (Hufnagel) (Jurenka et al. 1997), 
and larvae of the butterfly, Colias eurytheme L. (Stanley et al. 1999), as well as larvae of the tenebrionid beetle, Zophobas atratus (Fabricius) (Miller et al. 1996). These species are all members of the Endopterygota (the term preferred by Daly et al. [1998] over Holometabola). We also investigated the Exopterygota, including adults of the cricket, Gryllus assimilis (Fabricius) (Miller et al. 1999), adults of two species of 17year periodical cicadas, Magicicada septendecim L. and $M$. cassini L. (Tunaz et al. 1999), and adult cockroaches Periplaneta americana (L.)(Tunaz \& Stanley, 2000). The results of these experiments similarly support the idea that eicosanoids mediate microaggregation and nodulation reactions to bacterial infections.

Microaggregation and nodulation reactions are complex cellular activities, which entail a series of discrete steps, the exact number of which remains unknown. Work with waxmoths, Galleria mellonella L. showed that eicosanoids mediate two steps in the overall process (Mandato et al. 1997). One is cell spreading, which involves cytoskeleton rearrangements and the other is the final melanization step, which depends on activation of prophenyloxidase. In the same report, they noted that phagocytosis also depends on eicosanoids. Morishima et al. (1997) added a new level of information by investigating the possibility that expression of genes encoding anti-bacterial proteins also requires eicosanoid biosynthesis. Experimental larvae of the silkworm, B. mori, were injected with a pharmaceutical inhibitor of eicosanoid biosynthesis after which immune genes were stimulated by injecting soluble peptidoglycan prepared from the bacterium Bacillus licheniformis. After 1h incubation, total RNA was extracted from fat body and blotted onto membranes. The membranes were probed for the presence of mRNA encoding the antibacterial protein cecropin B and the antibacterial enzyme lysozyme. They found that expression of the genes for these two proteins was reduced by approximately $50 \%$ in experimental larvae. The authors also recorded similar results using in vitro preparations of isolated fat body. They interpreted their findings to suggest that eicosanoids are among the signaling moieties involved in expression of two genes encoding immune proteins.

While all results have so far bolstered the idea that eicosanoids mediate immune reactions in insects, and likely other invertebrates, the experimental protocols are attended by theoretical problems. For one, we assessed the possibility that eicosanoids are involved in immune reactions by treating the experimental insects with more or less selective pharmaceutical inhibitors of eicosanoid biosynthesis (Miller \& Stanley 1998a). So far, the pharmacology of only one of these inhibitors has been studied in an invertebrate. Miller \& Stanley (1998b) described the uptake, metabolism and elimination of indomethacin, a PG biosynthesis inhibitor, by tobacco hornworms. Whereas indomethacin is rapidly metabolized in mammals, most of the injected indomethacin recovered from hornworm tissues was intact. Indomethacin was metabolized into polar products after coming into contact with microbes in frass, from which we inferred that this pharmaceutical product is rapidly distributed among hornworm tissues, where it undergoes very little metabolism until it is cleared from the tissues and moved into the alimentary canal for excretion. In biochemical experiments we also found that indomethacin inhibits PG biosynthesis by in vitro enzyme preparations (Stanley-Samuelson \& Ogg 1994). Hence, we proposed that indomethacin is an appropriate probe for PG biosynthesis in insects (Miller \& Stanley 1998b).

Another theoretical issue is even more basic to assessing the roles of eicosanoids in insect biology. A base assumption is that the experimental organisms are competent to biosynthesize eicosanoids. We addressed this issue by documenting the presence of major elements of eicosanoid biosynthesis systems in insect immune tissues (Fig. 1). The first step in eicosanoid biosynthesis is thought to be the release of 20: $4 n-6$ from cellular phospholipids by action of a cytosolic phospholipase $\mathrm{A}_{2}\left(\mathrm{cPLA}_{2}\right)$. We characterized a cPLA $\mathrm{A}_{2}$ in tobacco hornworm fat body (Uscian \& Stanley-Samuelson 1993) and hemocytes (Schleusener \& Stanley-Samuelson 1996). These exercises revealed the intracellular cPLA $\mathrm{S}_{2}$ associated with these tissues are calcium-independent enzymes, which in mammals are thought to regulate eicosanoid biosynthesis (Dennis 1997, Balsinde et al. 1999).

We also characterized eicosanoid biosynthesis in the hornworm fat body (Stanley-Samuelson \& Ogg 1994) and hemocytes (Gadelhak et al. 1995), the main immunityconferring tissues. $\mathrm{PGA}_{2}$, the major fat body product, is thought to influence gene expression in mammalian systems (Negishi et al. 1995). Taken with the work of Morishima et al. (1997), the biosynthesis of PGA in fat body suggests the intriguing possibility that $\mathrm{PGA}_{2}$ regulates expression of genes encoding the antibacterial proteins cecropin D and lysozyme. Eicosanoid biosynthesis in hemocytes differs from the findings with fat body. The major hemocyte product was tentatively identified as the lipoxygenase product 15 hydroxyeicosatetraenoic acid (Gadelhak et al. 1995). These studies document the capability of tobacco hornworm immune tissues to biosynthesize eicosanoids.

While this work supports the eicosanoid hypothesis, the supporting arguments are circumstantial. First, treating insects with pharmaceutical inhibitors of eicosanoid biosynthesis impaired various immune reactions to bacterial infections. Second, the biochemical studies document the presence of eicosanoid biosynthetic systems. This reasoning does not make the crucial connection between a bacterial infection and a subsequent alteration in eicosanoid biosynthesis. We developed a new protocol to assess the influence of bacterial infections on eicosanoid biosynthesis (Jurenka et al. 1999). True armyworms, $P$. unipuncta, were injected with heat-killed bacteria, Serratia marcescens. After 30-minute incubations, hemolymph was collected and eicosanoids extracted. The extracts were cleaned up, then fluorescent derivatives were prepared by reacting the samples with 9-anthryldiazomethane. Individual components were separated on a high-pressure liquid chromatograph, and detected on a flow-through fluorescent detector. $\mathrm{PGF}_{2 a}$ was the major hemolymph PG. Samples taken from saline-injected controls yielded $0.9 \mathrm{pg} /$ $\mathrm{ml}$ hemolymph of $\mathrm{PGF}_{2 \mathrm{a}}$ compared to $4.0 \mathrm{ng} / \mathrm{ml}$ hemolymph for bacteria-injected experimental larvae. The fluorescent chromatograms also indicated increases in other eicosanoids, which remain to be identified. We concluded that increased amounts of PGs and other eicosanoids are biosynthesized 
following bacterial infections. This conclusion strongly supports the eicosanoid hypothesis.

Another issue in the work with PGs is careful identification of the compounds. In the work just mentioned, we confirmed the identification of $\mathrm{PGF}_{2}$ by analysis on gas chromotographymass spectrometry (GC-MS). We similarly determined the structure of $\mathrm{PGA}_{2}$ in our studies with true armyworm (Tunaz et al. 2001). PGs are present in very low amounts in insect tissues, which calls for careful attention to experimental details. The PGs must be derivatized before GC-MS analysis, and due to the charged nature of the compounds, the analytes are easily lost during the preparation procedures. We found, for example, that sample recovery after clean up on silica columns is enhanced by using acidified silica in the columns. A representative mass spectrum of $\mathrm{PGE}_{2}$ from midgut tissue of the tobacco hornworm, M. sexta, is shown in Fig. 2.

One of our current efforts is directed toward identifying specific bacterial components, which elicit eicosanoidmediated cellular defense reactions. Toward this end, we recently reported that the lipopolysaccharide (LPS) component of the bacterium $S$. marcescens stimulates microaggregation and nodulation reactions within minutes following injection into the hemocoels of larval beetles, Z. atratus (Bedick et al. 2000). More important to our work, eicosanoids mediate these reactions in response to a purified chemical. In vertebrates and invertebrates LPS is recognized by interaction with specific binding proteins (Charalambidis et al. 1996).

We are now poised to investigate the immediate biochemical reactions that follow the interaction between cellular binding proteins and LPS. Our preliminary work reveals increased hemocyte cPLA 2 activity immediately following infection. As seen in Fig. 1, the cPLA, step is thought to be the first step in eicosanoid biosynthesis, and we recorded increased cPLA $\mathrm{A}_{2}$ activity within 15 seconds following infection. While it is clearly important, the mechanism of activating this enzyme has not yet been investigated.

\section{Eicosanoids in Host-Parasite Relationships}

Possibly one of the most profound - and least explored roles of eicosanoids in animal biology relates to their actions in mediating certain host-parasite relationships. Relationships of this sort are very intimate and complex. Eicosanoids, as is true for many other chemicals, could potentially act in many ways. In this section we mention a few eicosanoid actions in parasitology, then give an overview of current work in our laboratory on an insect host-parasite relationship.

Leid \& McConnell $(1983 a, b)$ investigated the possibility that an endoparasitic worm, the tapeworm Taenia taeniaeformis (Platyhelminthes), was competent to

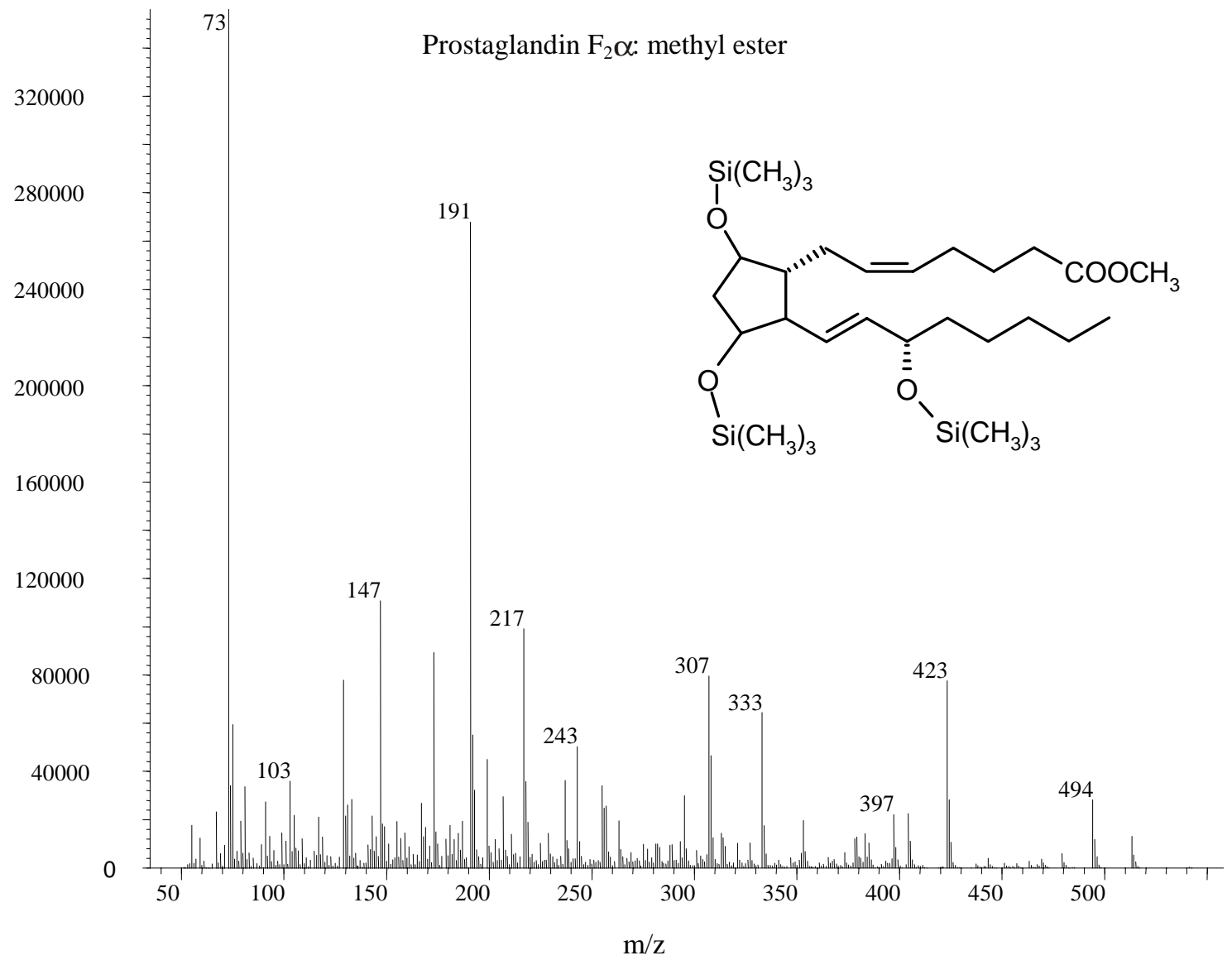

Figure 2. A total ion scan of the methyl ester trimethylsilyl derivative of $\mathrm{PGF}_{2 \mathrm{a}}$ prepared from midguts of the tobacco hornworm, M. sexta. 
biosynthesize eicosanoids. They showed that the tapeworms produced and secreted three eicosanoids, thromboxane $\mathrm{B}_{2}$ (a stable product of thromboxane $\mathrm{A}_{2}$ ), $\mathrm{PGE}_{2}$ and $\mathrm{PGI}_{2}$. The importance of this work, however, lies in their hypothesis relative to the biological significance of eicosanoid biosynthesis in the worms. They suggested that the eicosanoids were released by the worms into host tissues, where they act to attenuate host cellular defense reactions to the presence of the worm (Leid \& McConnell 1983a). The idea that parasites might manipulate host immunity by secreting eicosanoids into host tissues now echoes, albeit faintly, throughout the field of parasitology.

Subsequent workers came to similar conclusions with several species of endoparasites, including the cestodes (Platyhelminthes) Spirometra erinacei Fukushima et al. (1993) and T. multiceps (Rakha et al. 1996), the blood fluke Schistosoma mansoni (Trematoda; Fusco et al. 1993), three species of microfilariae (the nematodes responsible for lymphatic filariasis), Wuchereria bancrofti, Brugia malayi and B. timori (Liu \& Weller 1992), and another nematode, Oesophagostonum dentatum (Daugschies 1996). The idea takes on considerable urgency with the report from Kubata et al. (1998), showing that Plasmodium falciparum, the organism responsible for the most serious form of human malaria, secretes immunosuppressive PGs. Again, the authors speculated that the PGs secreted by the parasite act to manipulate host defense mechansims.

The idea is not limited to endoparasitic invertebrates. Ticks are obligate ectoparasites which feed on vertebrate blood. Tick saliva is rich in PGs, and ticks secrete copious amounts of saliva into the wounds of their hosts. The idea that the PGs serve the ticks by attenuating host immune reactions to the presence of the ticks has been put forth very clearly by Ribeiro (1987) and Sauer et al. (1993).

Of course invertebrate parasites are also physiological entities, and eicosanoids serve several physiological roles in invertebrates. Fusco et al. (1986) reported that rates of penetrating host skin by cercarial larvae of S. mansoni is influenced by lipoxygenase products. Similarly, eicosanoids influence migration behavior in $O$. dentatum (Daugschies \& Ruttkowski 1998). Hence, eicosanoids influence parasite behaviors that somehow facilitate gaining entry to potential hosts. Daugschies (1996) also suggested that eicosanoids mediate unspecified physiological actions within parasites, which can be registered in terms of growth and development.

The larval forms of some dipteran insects live as parasites in mammalian tissues, and this form of parasitic life history produces a disease condition known as myiasis. The primary screwworm, Cochliomyia hominivorax (Coquerel) is a serious myiasis-causing pest of cattle and humans in the New World tropics. Adults of this species lay eggs near openings in host skin, usually wounds. The insects develop through three larval stages in their hosts, then drop to the ground, where they go through the pupal stage and emerge as free-living adults. The screwworms seem to go through their developmental excursion in very little contact with host immune cells. On the basis of this observation, we erected the hypothesis that screwworms produce and secrete immuno-suppresive PGs into their vertebrate hosts.

The primary screwworm is a quarantine species, now eradicated from North America. Screwworms are maintained in a biocontainment facility by the USDA-ARS Midwest Livestock Insect Laboratory, and our work on this species is done in collaboration with the USDA laboratory.

We began our investigation by determining the presence of arachidonic acid in screwworms. Analyses on GC revealed relatively high proportions of arachidonic acid in phospholipids prepared from larvae and adults (Nor Aliza et al. 1999). On the understanding that the screwworms were reared on an artificial diet based on bovine blood and whole egg, we considered the idea that screwworms must elaborate a digestive phospholipase $\mathrm{A}_{2}$ that is responsible for hydrolyzing arachidonic acid from dietary phospholipids for absorption across the midgut epithelium of the screwworms. Characterization studies showed that this enzyme is sensitive to $\mathrm{pH}$ and temperature; it requires calcium for full catalytic potential and is sensitive to a site-specific inhibitor, oleyloxyethylphosphorylcholine. By these criteria, the digestive phospholipase $A_{2}$ from screwworm midguts is similar to mammalian digestive phospholipases $\mathrm{A}_{2}$ (Nor Aliza et al. 1999).

We are now assessing PG biosynthesis in third-stage screwworms. For these studies, the alimentary canals are removed from the screwworms, and homogenates of the remaining tissues are prepared for enzyme sources. These studies are producing evidence of PG biosynthesis by screwworm tissues. The major products are $\mathrm{PGE}_{2}, \mathrm{PGD}_{2}$, $\mathrm{PGF}_{2 \mathrm{a}}$ and $\mathrm{PGA}_{2}$; so far, there is no evidence of lipoxygenase activities. We also have preliminary data on the secretion of PGs into the media surrounding screwworms. The outcomes of these exercises add fuel to a smoldering fire: eicosanoids are very important mediators of relationships between mammalian hosts and representatives of most major invertebrate parasites, including insect parasites of mammals.

\section{The Significance of Research into Eicosanoids in Insect Biology}

In this essay we discussed past and current work on the roles of eicosanoids in two important areas of insect biology, immunity and host-parasite relationships. Eicosanoids act as signal moieties, and thereby serve in the regulation, integration and coordination of cellular and organismal activities. Research on chemicals which act as signals has three main lines of significance. For one, the research will yield insights into the mechanisms which regulate and coordinate events. For another, specific pharmaceutical compounds can be used as tools with which to identify and isolate in time specific cellular actions, such as discrete actions in the nodulation process. Finally, the idea that eicosanoids mediate both insect immune reactions and host-parasite relationships opens widely a new window onto the potentials to recognize new biochemical targets that may be exploited in future research on insect pest management. 


\section{A Research Prospectus - Future Eicosanoid Research}

A more complete understanding of the biology of eicosanoids draws attention to the cellular mechanisms of eicosanoid actions (Fig. 3). Here, we consider the mechanism of PG signal transduction which is drawn from the literature on mammals. Most PGs interact with specific G-protein coupled receptors located on cell surfaces (Negishi et al. 1995). When present at the cell surface, a PG can act as the natural agonist for its receptor, which in turn influences a related G-protein. The G-protein then influences an effector protein which may alter the intracellular concentration of a second messenger. $\mathrm{PGE}_{2}$, for example, interacts with at least four surface receptors. The $\mathrm{EP}_{1}$ receptor increases phosphoinositol turnover, with elevation in intracellular free calcium ions. The $\mathrm{EP}_{2}$ and $\mathrm{EP}_{4}$ receptors increase adenylate cyclase activity, which increases intracellular cAMP concentrations, while most $\mathrm{EP}_{3}$ receptors have the opposite effect. Inquiry into eicosanoid signal transduction mechanisms is one of the key frontiers, which until now remains virtually unexplored (Fig. 3).

Similarly, while the last decade has seen tremendous progress in the molecular biology of mammalian eicosanoid systems, this is another dark frontier awaiting the illuminating work of entomologists. We have begun some work in this area, with a collaborative effort to clone the gene for cyclooxygenase in the tobacco hornworm fat body. So far, work with primers based on the mammalian genes has not revealed the insect gene. Nonetheless, we anticipate considerable progress in this vein.

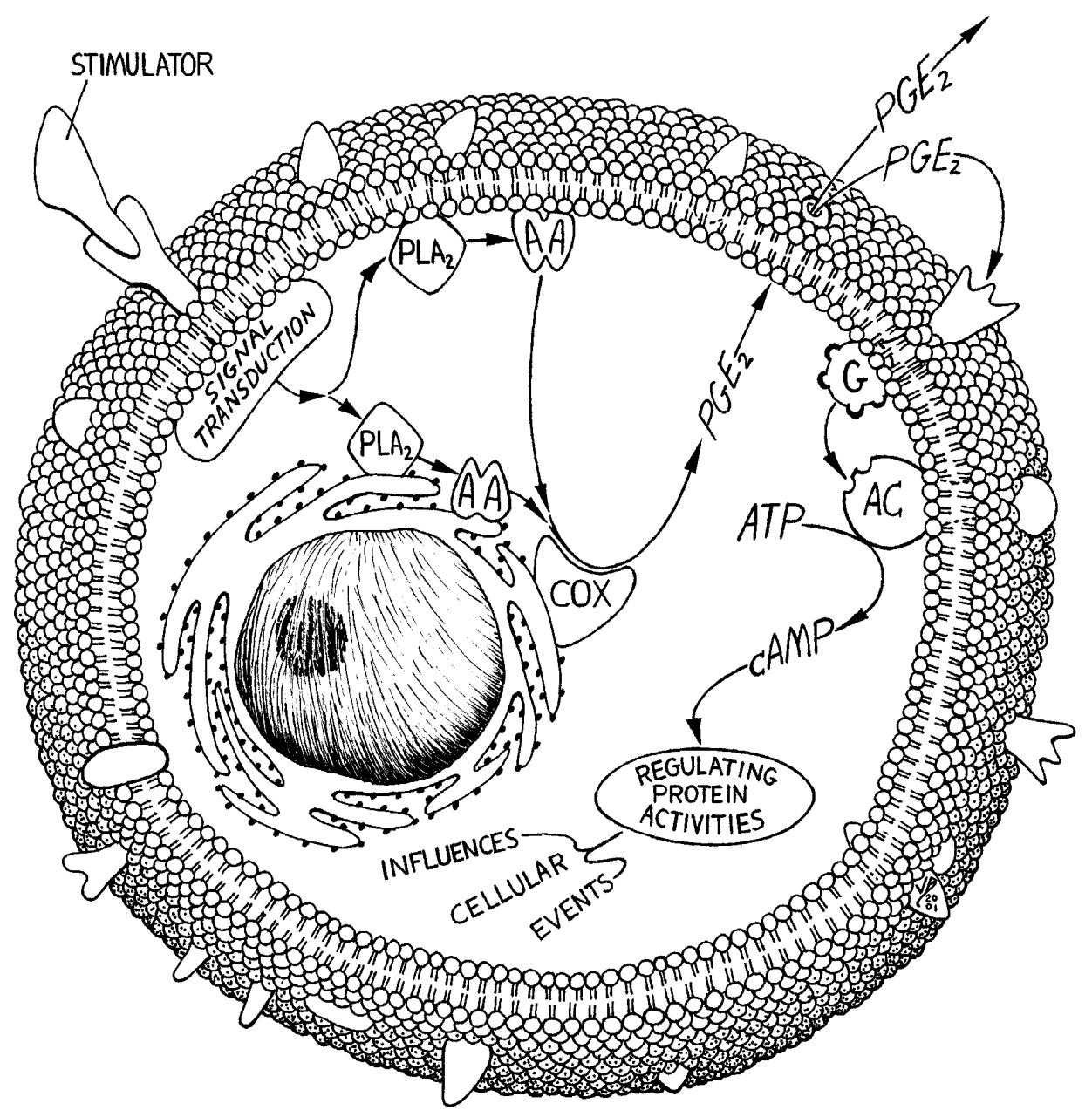

Figure 3. An overview of the cellular actions of PGs, one group of eicosanoids. In this view, a stimulator (which could be a hormone or other physiological mediator or a chemical associated with an infectious agent) interacts with specific cell surface receptors. This interaction stimulates cPLA2 activity, which releases arachidonic acid (AA) from phospholipid components of cellular membranes. The AA is oxygenated into a PG, in this illustration PGE, by cyclooxygenase (COX), the central enzyme in PG biosynthesis. Via action of specific PG transporter proteins, the PGs can be exported from the cell, where they might function in an autocrine mode by interacting with PG receptors on the external surface of the cell, or work in a paracrine mode by interacting with receptors on other cells. The PG signals are transduced to the intracellular space through receptor coupling to $\mathrm{G}$ proteins, which in this case shown to influence intracellular concentrations of cAMP. 


\section{Acknowledgments}

We thank Dr. John E. Foster for a kind invitation to develop this Forum article. This is paper number 13,774 of the Nebraska Agricultural Research Division. Work in our laboratory is supported by the Agricultural Research Division, UNL (Project NEB-17-054) and by USDA-ARS Specific Cooperative Agreement \#58-5430-5-115.

\section{Literature Cited}

Balsinde, J., M.A. Balboa, P.A. Insel \& E.A. Dennis. 1999. Regulation inhibition of phospholipase $\mathrm{A}_{2}$. Annu. Rev. Pharmacol. Toxicol. 39: 175-189.

Bedick, J.C., R.L. Pardy, R.W. Howard \& D.W. Stanley. 2000. Insect cellular reactions to the lipopolysaccharide component of the bacterium Serratia marcescens are mediated by eicosanoids. J. Insect Physiol. 46: 14811487

Bergstrom, S., R. Ryhage, B. Samuelsson \& J. Sjovall. 1962. The structure of prostaglandin $\mathrm{E}, \mathrm{F}_{1}$, and $\mathrm{F}_{2}$. Acta Chem. Scan. 16: 501-502.

Carton, Y. \& A.J. Nappi. 2001. Immunogenetic aspects of the cellular immune response of Drosophila against parasitoids. Immunogenetics 52: 157-164.

Charalambidis, N.D., L.C. Foukas, C.G. Zervas \& V.J. Marmaras. 1996. Hemocyte surface phenoloxidase (PO) and immune response to lipopolysaccharide (LPS) in Ceratitis capitata. Insect Biochem. Molec. Biol. 26: 867-874.

Chernysh, S., S. Cociancich, J.-P. Briand, C. Hetru \& P. Bulet. 1996. The inducible antibacterial peptides of the Hemipteran insect Palomena prasina: identification of a unique family of proline-rich peptides and of a novel insect defensins. J. Insect Physiol. 42: 81-89.

Corey, E.J., J.O. Albright, A.E. Barton \& S. Hashimoto. 1980. Chemical and enzymic syntheses of 5-HPETE, a key biological precursor of slow-reacting substance of anaphylaxis (SRS) and 5-HETE. J. Am. Chem. Soc. 102: 1435-1436.

Daly, H.V., J.T. Doyen \& A.H. Purcell III. 1998. Introduction to insect biology and diversity. Oxford, Oxford Univ. Press, 680p.

Daugschies, A. 1996. Investigations into the production and function of leukotrienes during histotropic development of Oesophagostomum detatum. Parasitol. Res. 82: 416-422.

Daugschies, A. \& B. Ruttkowski. 1998. Modulation of migration of Oesophagostomum detatum larvae by inhibitors and products of eicosanoid metabolism. Internat. J. Parasitol. 28: 355-362.
Dennis, E.A. 1997. The growing phospholipase $A_{2}$ superfamily of signal transduction enzymes. Trends. Biochem. Sci. 22: 1-2.

Destephano, D.B. \& U.E. Brady. 1977. Prostaglandin and prostaglandin synthetase in the cricket, Acheta domesticus. J. Insect Physiol. 23: 905-911.

Dunn, P.E. 1986. Biochemical aspects of insect immunity. Annu. Rev. Entomol. 31: 321-339.

Euler, U.S. von 1936. On the specific vasodilating and plain muscle stimulating substances from accessory genital glands in men and certain animals (prostaglandin and vesiglandin). J. Physiol. 88: 213-234.

Fukushima, T., A. Isobe, N. Hojo, K. Shiwaku, Y. Yamane \& M. Torii. 1993. The metabolism of arachidonic acid to prostaglandin $\mathrm{E}_{2}$ in plerocercoids of Spirometra erinacei. Parasitol. Res. 79: 634-638.

Fusco, A.C., B. Salafsky \& K. Delbrook. 1986. Schistosoma mansoni: production of cercarial eicosanoids as correlates of penetration and transformation. J. Parasitol. 73: 397-404.

Fusco, A.C., B. Salafsky \& T. Shibuya. 1993. Cytokine and eicosanoid regulation by Schistosoma mansoni during LSE penetration. Mediators Inflamm. 2: 73-77.

Gadelhak, G.G., V.K. Pedibhotla \& D.W. StanleySamuelson. 1995. Eicosanoid biosynthesis by hemocytes from the tobacco hornworm, Manduca sexta. Insect Biochem. Molec. Biol. 25: 743-749.

Gillespie, J. P., M.R. Kanost \& T. Trenczek. 1997. Biological mediators of insect immunity. Annu. Rev. Entomol. 42: 611-643.

Horohov, D.W. \& P.E. Dunn. 1983. Phagocytosis and nodule formation by hemocytes of Manduca sexta larvae following injection of Pseudomonas aeruginosa. J. Invertebr. Pathol. 41: 203-213.

Jurenka, R.A., J.S. Miller, V.K. Pedibhotla, R.L. Rana \& D.W. Stanley-Samuelson. 1997. Eicosanoids mediate microaggregation and nodulation responses to bacterial infections in black cutworms, Agrotis ipsilon, and true armyworms, Pseudaletia unipuncta. J. Insect Physiol. 43: 125-133.

Jurenka, R.A., V.K. Pedibhotla \& D.W. Stanley. 1999. Prostaglandin production in response to a bacterial infection in true armyworm larvae. Arch. Insect Biochem. Physiol. 41: 225-232.

Kubata, B.K., N. Eguchi, Y. Urade, K. Yamashita, T. Mitamura, K. Tai, O. Hayaishi \& T. Horii. 1998. Plasmodium falciparum produces prostaglandins 
that are pyrogenic, somnogenic, and immunosuppressive substances in humans. J. Exp. Med. 188: 1197-1202.

Leid, R.W. \& L.A. McConnell. 1983a. Thromboxane $A_{2}$ generation by the larval cestode, Taenia taeniaeformis. Clinical Immunol. Immunopathol. 28: 67-76.

Leid, R.W. \& L.A. McConnell. 1983b. PGE ${ }_{2}$ generation and release by the larval stage of the cestode, Taenia taeniaeformis. Prostaglandins, Leukotrienes and Medicine 11: 317-323.

Liu, L.X. \& P.F. Weller. 1992. Intravascular filarial parasites inhibit platelet aggregation. Role of parasite-derived prostanoids. J. Clin. Invest. 89: 1113-1120.

Mandato, C.A., W.L. Diehl-Jones, S.J. Moore \& R.G.H. Downer. 1997. The effects of eicosanoid biosynthesis inhibitors on prophenoloxidase activation, phagocytosis and cell spreading in Galleria mellonella. J. Insect Physiol. 43: 1-8.

Miller, J.S. \& D.W. Stanley. 1998a. The nodule formation reaction to bacterial infection: Assessing the role of eicosanoids, p. 265-270. In A. Wiesner, G.B. Dunphy, V.J. Marmaras, I. Morishima, M. Sugumaran, \& M. Yamakawa (eds.), Techniques in insect immunology. Fair Haven, NJ, SOS Publications, 304p.

Miller, J.S. \& D.W. Stanley. 1998b. The pharmacology of indomethacin, a prostaglandin biosynthesis inhibitor, in larvae of the tobacco hornworm, Manduca sexta.. J. Insect Physiol. 42: 893-901.

Miller, J.S., R.W. Howard, R.L. Rana, H. Tunaz \& D.W. Stanley. 1999. Eicosanoids mediate nodulation reactions to bacterial infections in adults of the cricket, Gryllus assimilis. J. Insect Physiol. 45: 75-83.

Miller, J.S., R.W. Howard, T. Nguyen, A. Nguyen, R.M.T. Rosario \& D.W. Stanley-Samuelson. 1996. Eicosanoids mediate nodulation responses to bacterial infections in larvae of the tenebrionid beetle, Zophobas atratus. J. Insect Physiol. 42: 3-12.

Miller, J.S., T. Nguyen \& D.W. Stanley-Samuelson. 1994. Eicosanoids mediate insect nodulation responses to bacterial infections. Proc. Natl. Acad. Sci. USA 91: 12418-12422.

Morishima, I., Y. Yamano, K. Inoue \& N. Matsuo. 1997. Eicosanoids mediate induction of immune genes in the fat body of the silkworm, Bombyx mori. FEBS Letters 419: 83-86.

Negishi, M., T. Koizumi \& A. Ichikawa. 1995. Biological actions of $?^{12}$-prostaglandin $\mathrm{J}_{2}$. J. Lipid Mediators Cell Signalling 12: 443-448.
Nor Aliza, A.R., R.L. Rana, S.R. Skoda, D.R. Berkebile \& D.W. Stanley. 1999. Tissue polyunsaturated fatty acids and a digestive phospholipase $\mathrm{A}_{2}$ in the primary screwworm, Cochliomyia hominivorax. Insect Biochem. Molec. Biol. 29: 1029-1038.

Oates, J.A. 1982. The 1982 Nobel prize in physiology or medicine. Science 218: 765-768.

Rakha, N.K., J.B. Dixon \& S.D. Carter. 1996. Taenia multiceps (cestoda): Ia antigen expression and prostaglandin secretion by parasite-modified murine peritoneal macrophages. Parasite 3: 135-141.

Ribeiro, J.M.C. 1987. Role of saliva in blood-feeding by arthropods. Annu. Rev. Entomol. 32: 463-478.

Rowley, A.F. 1996. The evolution of inflammatory mediators. Mediators Inflamm. 5: 3-13.

Samuelsson, B. 1983. Leukotrienes: mediators of immediate hypersensitivity reactions and inflammation. Science 220: $568-575$

Sauer, J.R., A.S. Bowman, M.M. Shipley, C.L. Gangler, M.R. Surdick, J.L. McSwain, C. Luo, R.C. Essenberg \& J.W. Dillwith. 1993. Arachidonate metabolism in tick salivary glands, p. 99-138. In D.W. Stanley-Samuelson and D.R. Nelson (eds.), Insect lipids: chemistry, biochemistry, and biology. Lincoln, Univ. Nebraska Press, 467p

Schleusener, D.R. \& D.W. Stanley-Samuelson. 1996. Phospholipase $\mathrm{A}_{2}$ in hemocytes of the tobacco hornworm, Manduca sexta. Arch. Insect Biochem. Physiol. 33: 6374.

Stanley, D.W. 2000. Eicosanoids in Invertebrate Signal Transduction Systems. Princeton, Princeton Univ. Press, $277 \mathrm{p}$.

Stanley, D.W., W.W. Hoback, J.C. Bedick, H. Tunaz, R.L. Rana, A.R. Nor Aliza \& J.S. Miller. 1999. Eicosanoids mediate nodulation reactions to bacterial infections in larvae of the butterfly, Colias eurytheme. Comp. Biochem. Physiol. Part C 123: 217-223.

Stanley-Samuelson, D.W. \& C.L. Ogg. 1994. Prostaglandin biosynthesis by fat body from the tobacco hornworm, Manduca sexta. Insect Biochem. Molec. Biol. 24: 481491.

Stanley-Samuelson, D.W., E. Jensen, K.W. Nickerson, K. Tiebel, C.L. Ogg \& R.W. Howard. 1991. Insect immune response to bacterial infection is mediated by eicosanoids. Proc. Natl. Acad. Sci. USA 88: 1064-1068.

Stanley-Samuelson, D.W., V.K. Pedibhotla, R.L. Rana, A.R. Nor Aliza, W.W. Hoback \& J.S. Miller. 1997. 
Eicosanoids mediate nodulation responses to bacterial infections in larvae of the silkmoth, Bombyx mori. Comp. Biochem. Physiol. 118A: 93-100.

Strand, M.R. \& L.L. Pech. 1995. Immunological basis for compatibility in parasitoid-host relationships. Annu. Rev. Entomol. 40: 31-56.

Tunaz, H. \& D.W. Stanley. 2000. Eicosanoids mediate nodulation reactions to bacterial infections in adults of the American cockroach, Periplaneta americana (L.). Proc. Entomol. Soc. Ontario 130: 97-108.

Tunaz, H., J.C. Bedick, J.S. Miller, W.W. Hoback, R.L. Rana \& D.W. Stanley. 1999. Eicosanoids mediate nodulation reactions to bacterial infections in adults of two 17-year periodical cicadas, Magicicada septendecim and M. cassini. J. Insect Physiol. 45: 923-931.

Tunaz, H., R.A. Jurenka \& D.W. Stanley. 2001. Prostaglandin biosynthesis by fat body from true armyworms, Pseudaletia unipuncta. Insect Biochem. Molec. Biol. 31: 435-444.

Uscian, J.M. \& D.W. Stanley-Samuelson. 1993. Phospholipase $\mathrm{A}_{2}$ activity in the fat body of the tobacco hornworm Manduca sexta. Arch. Insect Biochem. Physiol. 24: 187-201.

Weinheimer, A.J. \& R.L. Spraggins. 1969. The occurrence of two new prostaglandin derivatives (15-epi-PGA $A_{2}$ and its acetate methyl ester) in the gorgonian Plexaura homomalla: chemistry of coelentrates IV. Tetrahedron Lett. 59: 5185-5188. 